\title{
SPRING GYMNASTICS
}

\author{
By MISS J. BLAIR, M.c.s.P. (Teacher's Certificates):
}

Senior Lecturer in Physiotherapy University of the Witwatersrand.

TT exercises without a great deal of paraphernalia and equipment; and the private practitioner in particular, often finds herself in a position where her patient needs resistance at home, and there is difficulty in devising a method.

I put forward the following little unit (Diagram 1.) as being a suggestion in treating some of the patients.

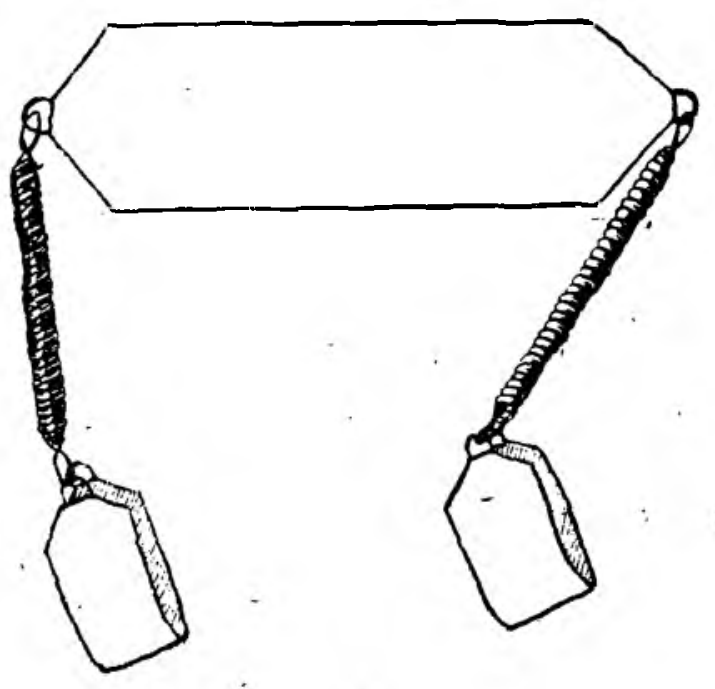

I.

With three slings and two springs there are many resisted exercises that can be performed and perhaps many others that could be.

For most of the leg exercises one sling is around the waist and one on each foot, the two springs, the weight of which is dependent on the patient's strength, placed in the circuit parallel with the legs (Diagram II). The patient is in long sitting and controls the tension of the springs with the position of her trunk and their angle of pull with her hands.

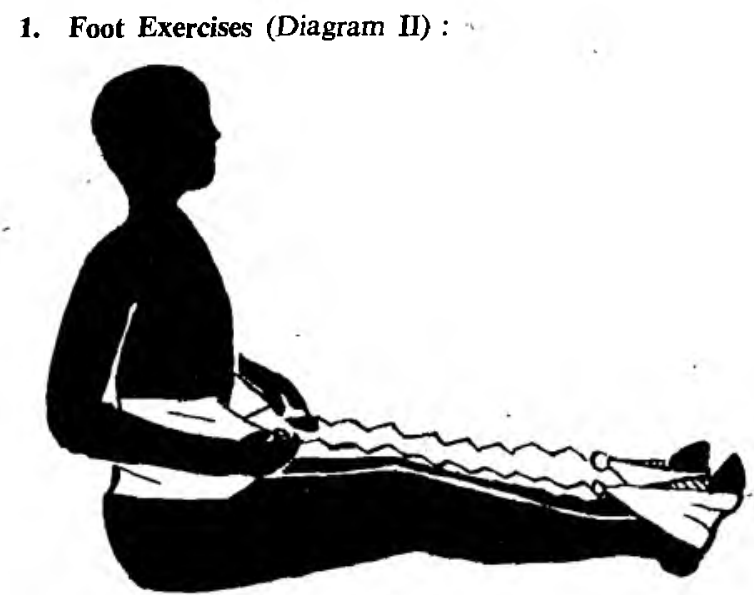

II.

With the springs on slight tension to begin with, all ankle and mid torsal joint movements are given against the resistance of the spring.

2. Hip and Knee Extension :

With the patient leaning back against the trunk sling, hip and knee extension is given alternatively, the direction of the spring being controlled by the patient's hand on the trunk belt and spring junction.

3. Hip Exercises :

(a) HIP UPDRAWING (Diagram III).

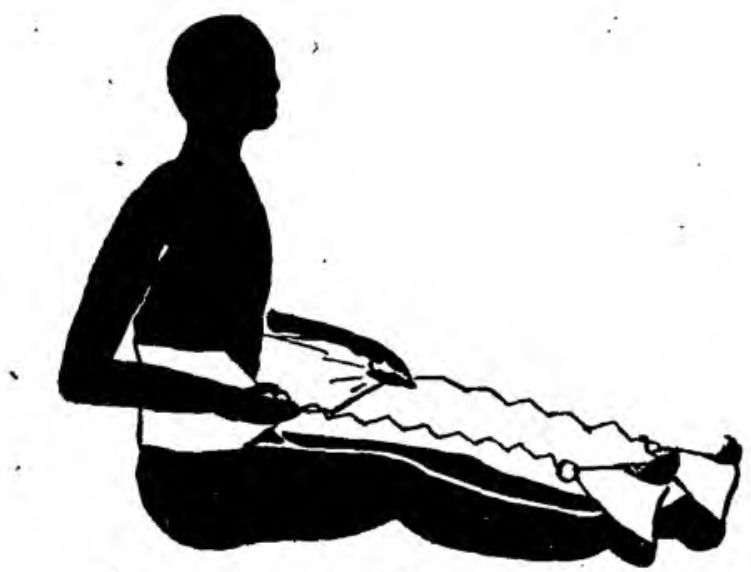

III. 
For this exercise the patient is in long sitting and both springs must be on slight tension to begin the exercise.

(b) LEG ABDUCTION AND ADDUCTION (Diagram IV).

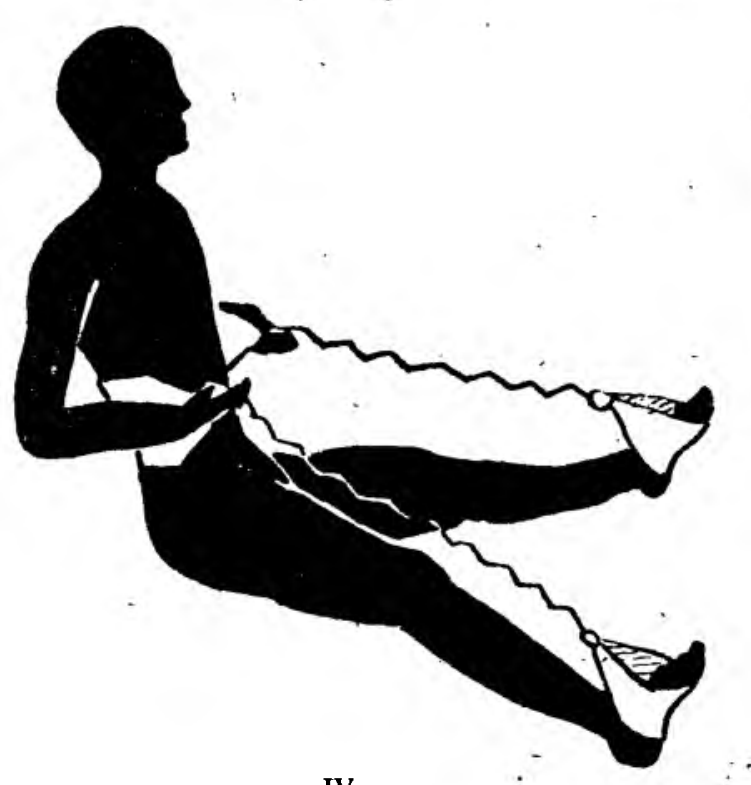

IV.

The patient leans back against the trunk sling until she is in the half lying position and the springs on tension; single or double leg abduction and adduction, circumduction or flexion can then be performed against resistance.

4. Trunk Exercises (Diagrams $V$ and VI).

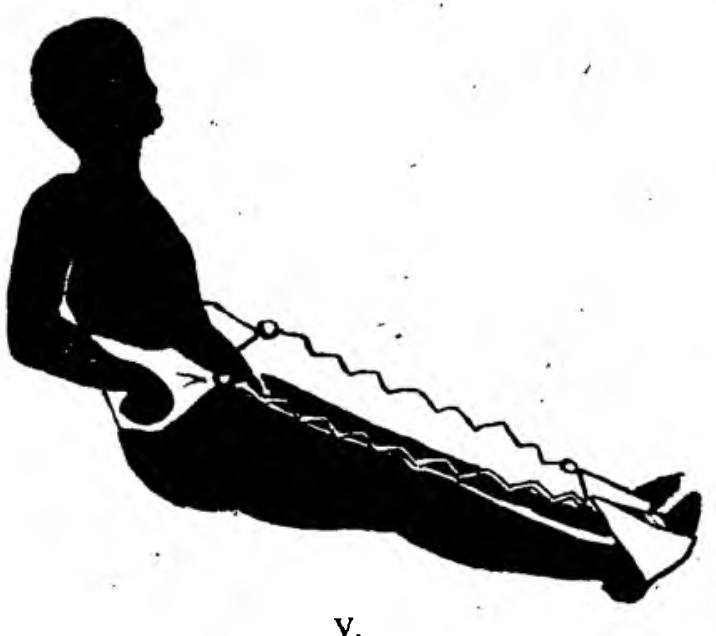

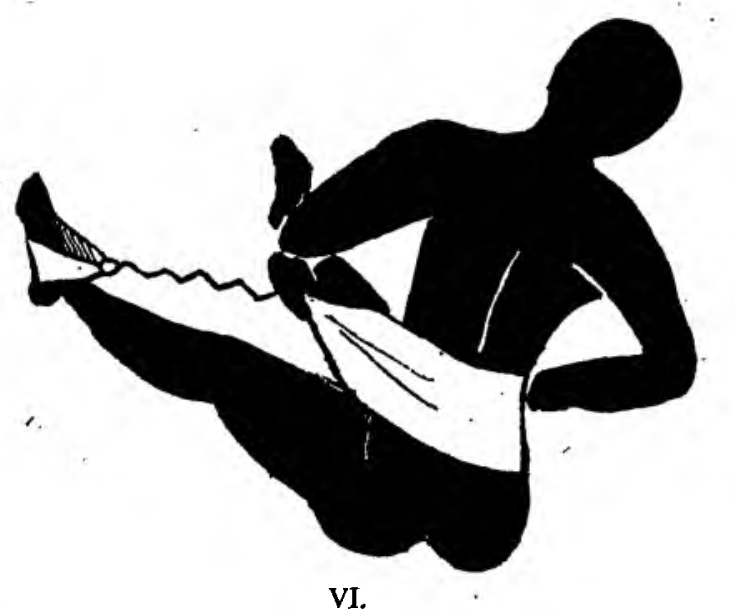

With the patient in long sitting and the arms in wing position or holding the sling spring junction; trunk extension, side flexion and rotation may be given, the tension of the springs being controlled by the position of the trunk, i.e. if increased resistance is required springs must be at a greater tension.

\section{Head Exercises (Diagram VII).}

For these exercises it is more comfortable for the patient to be in a crook sitting with the peripheral slings around the thighs if possible. The patient has a head rest position of the arms to guide and control the angle of pull of the springs and head sling.

Head extension, head and neck extension, head side flexion and head rolling are all possible against the resistance of the springs. An excellent home treatment for cervical osteoarthritis.

\section{Arm Exercises (Diagram VIII).}

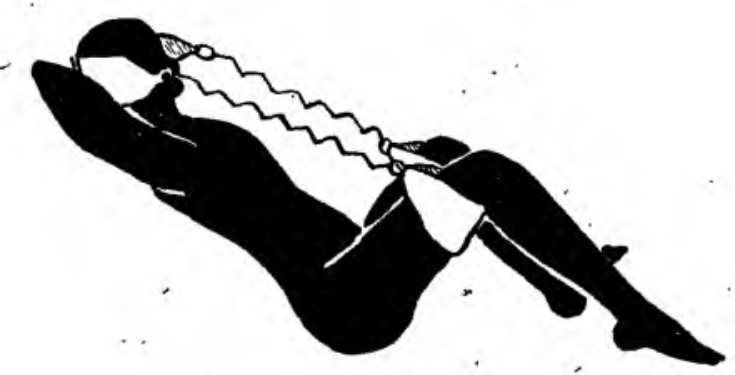

VII.

By detaching one sling and spring and having the circuit: sling-spring-sling, arm exercises can be performed with one sling on the leg for anchorage or fixation. This sling may be placed around the thighas in Diagram VIII, or around the foot depending on the required resistance and range of movement. 


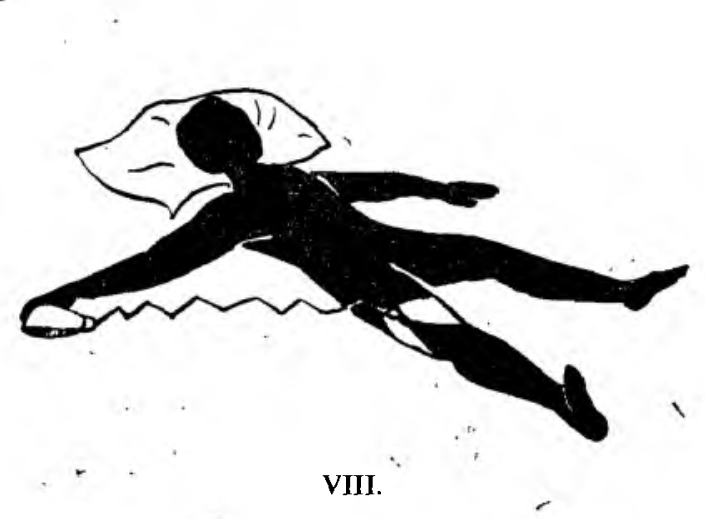

Similarly this unit may be equally well employed in giving leg exercises (Diagram IX), the arm or hand being the anchorage and the position of the arm controlling the angle of pull and tension of the spring.

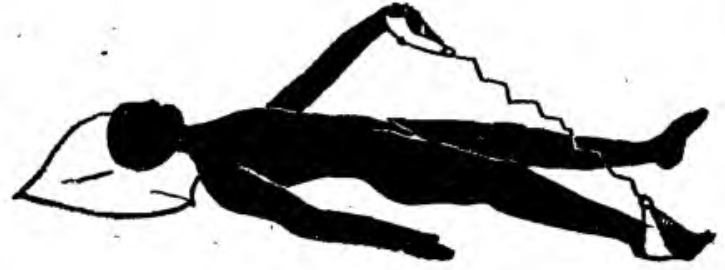

IX.

In this article I have deliberately not specified conditions for which these exercises can be used; that is up to the physiotherapist to adapt the basic idea to the needs of her individual patient.

These exercises are merely suggestions given in good faith, and I would most heartily appreciate other ideas and opinions on Spring Gymnastics. I am sure there is tremendous scope for simple methods of Rehabilitation. Mrs. Guthrie Smith has already blazed the trail, and an interchange of ideas is always a stimulus. May I hope that this is the first of many articles on similar lines?

\title{
AVALON
}

\section{A BRIEF ACCOUNT OF THE WORK DONE AT THE REHABILITATION CENTRE.}

\author{
By SUSIE OOSTHUIZEN, M.C.S.P., Superintendent.
}

$I^{\mathrm{N}}$ 1952 the Avalon Association for the rehabilitation of the Physically Handicapped transferred its Centre from Tulbach in the Cape to "Tussenkoppies" Farm near Johannesburg.

In the beginning this new centre, which was just a farm, had to be put into some sort of shape in order to accommodate 9 patients, and an old barn was converted into a gym, etc. At first it was doubtful whether there would be a demand for such a Centre. But soon, after some propaganda, it was discovereed that more accommodation would be necessary and the total was then brought up to 20 beds, and now the demand is so great that over 100 names are on the waiting list.

Cases are drafted from various organisations or directly. Among the organisations interested are: The Cripple Care Organisations, Hospitals, Welfare Organisations, Military Pensions Department, Social Welfare Departments, W.C.A. and Labour Departments and Doctors. A medical certificate is necessary in all cases applying for admission, which includes the history of the case, suggested lines of treatment, and probable duration of stay at the Centre. Close co-operation exists between all-these different departments and the Superintendent, and the services of honarary doctors are available at any time.

To quote examples of how the Centre operates from the co-ordination with allied organisations a short history is given below of Frankie Wright. Here was a boy who, at the age of 9 years, had his right leg amputated above the knee, due to osteomyelitis, and for the following 30 years he had a recurrent osteomyelitis in the left hip. The picture then was that Frankie sat in a chair, not even a wheelchair, with an amputated leg, a withering left leg with hip contractures, an increase in girth size, loss of muscle tone and a mental outlook which debarred him from any sort of social life. So, Frankie had not walked for $\mathbf{3 0}$ years.

On the 6th of February, 1953 this patient entered AVALON with new hope of walking again. Sling exercises were commenced and although the bone in the hip was very osteoporosed, the risk of attempting to straighten the leg in order to fit a weight bearing caliper was taken, and active assisted exercises were begun. During this period the Physiotherapy Department at the Johannesburg General Hospital very kindly assisted Avalon by giving ultra violet light with the Kromayer to the hip twice weekly for a period of three months. (It is interesting to note that the hip has been clear for 6 months).

The Social Welfare Department during this period, set to work to obtain the approval of the Health Department for the making of a prosthesis for the right leg and a caliper for the left leg. Once this order was sanctioned, the Government Artificial Limb Factory made the necessary appliances and then the teaching of walking started.

From the anti-social view point, ways and means to break down a 30 year old barrier had to be brought into the programme. This was started by introducing strangers to him, encouraging him to talk about his disability and encouraging him to attend places of entertainment in public. Outings in the company of other patients were constantly organized, various - public bodies visited the Centre, and soon Frankie not only started to talk about himself, but actually enjoyed doing so.

The final scene in his rehabilitation was when the Superintendent took him on a holiday, which made him 